\section{Health-seeking behaviour of Port Harcourt city residents: a comparison between the upper and lower socio-economic classes}

\author{
Promise Tamunoipiriala Jaja \\ University of Port Harcourt Teaching \\ Hospital, Port Harcourt, Rivers State, \\ Nigeria
}

\section{Abstract}

This study aimed at establishing the determinants and distribution of the health-seeking behaviours of Port Harcourt residents, and comparing them between the upper and lower socio-economic classes. A descriptive crosssectional study using 204 respondents was carried out. The socio-economic classification used occupation and average monthly income. Multi-staged sampling technique was used; stage one being by stratified sampling using socio-economic classes for stratification; stage two involved clustered sampling; following which five-sectioned structured questionnaires were administered. Differences $(\mathrm{P}<0.05)$ in Health facility used existed: the upper class used mostly Government and Private Hospitals; the lower class additionally used health centres and un-orthodox health facilities. Reasons for using a health facility was similar $(\mathrm{P}>0.05)$ as both classes mostly go for treatment or medical check-ups. Health facility preference was mostly for good treatment outcome and accessibility; cost also, for the lower class. Commonly and last used health-care giver differed $(\mathrm{P}<0.05)$; upper class mostly saw a doctor, the lower saw the doctor, pharmacist and nurse. Competence; the major reason for health-care giver selection by the upper class differed $(\mathrm{P}<0.05)$ from the lower that had previous good treatment outcome and illness severity. The upper socioeconomic classed have better health-seeking behaviours because they use more competent Health facilities and health-care givers.

\section{Introduction}

Health by no small measures adds value to life; little wonder why its scope as judged by the World Health Organization is not restricted to the physical absence of infirmity only but also includes the mental and social well-being of an individual. ${ }^{1,2}$ Health-seeking behaviours have been described as the sequence of remedial actions taken by an individual as a means to rectify perceived ill health; it is however significantly affected by the beliefs and attitudes of people (according to the Health Belief model). ${ }^{3,4}$ The treatment action-plan thus developed is usually consequent on the initiation of symptom definition. ${ }^{5}$

The attainment of good health has however been a theoretical expectation at the moment in many parts of the world, Port Harcourt in Nigeria not being an exception; a comparison of the mortality statistics for Nigeria and other African countries as well as the African regional average over time shows this. Infant mortality rate is seen as the most important indicator of the health status of a community; other indicators include the under-five mortality rate, maternal mortality rate, life expectancy at birth, nutritional status and fertility rate.,2,6,7 The inference from Table $1^{8}$ can thus point to a poor health status in Nigeria and Port Harcourt city by extension.

A defective health status is however thought to be due to a poor distribution of health facilities or impaired Health seeking and/or utilization behaviours; these behaviours in themselves are affected by socio-demographic factors, gender, educational, cultural and biological dynamics. ${ }^{2,5,9-11}$ Socio-economic status is widely accepted as a cardinal factor affecting seeking Health care of any sort at all; this thus closely relates health and health status to socio-economic status. ${ }^{5,6}$

This study aims at determining the distribution and determinants of the health-seeking behaviours of Port Harcourt residents, and comparing these amongst the upper and lower socio-economic classes, by so doing, it intends to provide information with which policy makers can effect transitive and people-oriented health policies.

\section{Materials and Methods}

The residents of the metropolitan town of Port Harcourt in Rivers state of Nigeria were chosen for this study, which used a descriptive cross-sectional study design. The study used a multi-staged sampling technique; the first stage being by stratified sampling using socioeconomic class as the stratification criteria, creating strata within Port Harcourt; the residents of the old government residential area for upper socio-economic class, while the residents of Azuabie town and marine-base area for the lower socio-economic class. The social and economic classifications used for the study are presented in Tables 2 and 3 . The upper social class and the high-income earners were grouped as upper socio-economic class and like manner for the middle and lower socio-economic classes.
Correspondence: Promise Tamunoipiriala Jaja, University of Port Harcourt Teaching Hospital, Port Harcourt, Rivers State, Nigeria.

E-mail:projat@hotmail.com

Key words: health-seeking behaviours, health systems management, public health.

Acknowledgements: I would like to thank my colleagues who were involved in the collection of the data used for this paper: Drs Akoko S, Iragunima $\mathrm{A} U$ and Bestman $\mathrm{A}$ as well as the Congregation of the Seventh-Day Adventist Church, Azuabie.

Received for publication: 26 January 2012 . Revision received: 18 December 2012. Accepted for publication: 26 May 2013.

This work is licensed under a Creative Commons Attribution NonCommercial 3.0 License (CC BYNC 3.0).

(C) Copyright P.T. Jaja et al., 2013

Licensee PAGEPress, Italy

Journal of Public Health in Africa 2013; 4:e9 doi:10.4081/jphia.2013.es

The second stage was by clustered sampling technique; the upper class stratum (Old G.R.A.) was grouped into 4 clusters based on the preexisting streets and road network from which one was taken (Abana, Ernest Ikoli and William Jumbo streets), the lower class stratum (Azuabie town and Marine Base area) was also grouped into clusters from which the Estate area (California, Government, Fishermen's and Blackman Estates) was taken from the Marine base area and the Azuabie town centre from the Azuabie town. This was followed by the use of a team of investigators and local contacts to carry out a structured questionnaire survey that occurred between January and March 2011.

The exclusion criteria for this study included people younger than 14 years, students, and residents with duration of residency less than six months prior to the study as well as members of the middle socio-economic class. A total of 204 respondents were utilized of the initial 240 questionnaires sent out; this gave a response rate of about $85 \%$.

The five-sectioned questionnaires used had sections for bio-data, concept of health, illness and Health facility as well as information on health-care givers. The questions were partly generated following literature search and partly from the investigators; the initial questionnaire developed was pre-tested using 24 respondents (comprised of student and nonstudent residents of the environs of the University of Port Harcourt), which were 10\% of the sample size for the study. After the pretesting, options for the remaining open-ended questions but one were generated (Appendix). 
The data were subsequently sorted and entered into Microsoft Excel ver. 2007 (Microsoft Corp., Redmond, WA, USA) for generation of tables and charts as well as calculation of proportions and standard deviations that were used to test for difference of proportions using the Z-test for difference of proportions according to Lwanga et al. ${ }^{12}$ The study had limitations that were especially the short duration of the study period which limited the possible expansion of the sample size.

\section{Results}

The 204 residents used showed a sex distribution that revealed that $131(64.22 \%)$ of the respondents were males, as against 73 (35.78\%) that were females.

The social class distribution had values as 83 (40.69\%), 28 (13.73\%) and 93 (45.58\%) for upper, middle and lower social classes respec- tively. The income earnings grouping based on average monthly earnings returned values as 102 (50.00\%), 12 (5.88\%) and 90 (44.12\%) for high, middle and low income earners respectively. Table 4 shows that most (65.69\%) of the upper social classed residents were also highincome earners and also similarly for the lower social class and low income earners. Most of the respondents with high level of education post-graduate (75.61\%) and tertiary (63.33\%) levels - were also of the upper social class, while most (91.43\%) of the respondents with secondary level of education were of the lower social class.

The perception of health amongst Port Harcourt residents showed no statistically significant difference $(\mathrm{P}>0.05)$ between the upper and lower socio-economic classes. Most [193 (94.61\%)] of the respondents think that some people are healthier than others; both compared socio-economic class groups agreed that people with educational level of tertiary and above as well as high income earners have better health. Other factors thought to account for better health include having adequate knowledge on health issues (22.41\%), eating good and balanced diet (20.69\%), having regular medical check-ups (19.83\%), having resources to take care of one's self (17.29\%), etc. The means of maintaining a state of wellness as perceived by the respondents were to have regular medical check-ups (42.17\%), treat any disease immediately (17.77\%), stay updated on recent and emerging health issues (16.57\%), etc.

Actions taken by Port Harcourt residents when ill include: seeking for help from any available source (76.58\%), take a rest alone or seek for health-help also (11.26\%), seek for advice from friends and relatives (3.15\%), etc. The knowledge of the respondents of some common health conditions were tested, using a scoring system with scores from $0-16$. The average knowledge score of all the respondents was $11.373 \pm 4.649$. The upper and lower social classed respondents had an average score of

Table 1. Trend of some health status indicators (culled from World Health Statistics, 2010). ${ }^{8}$

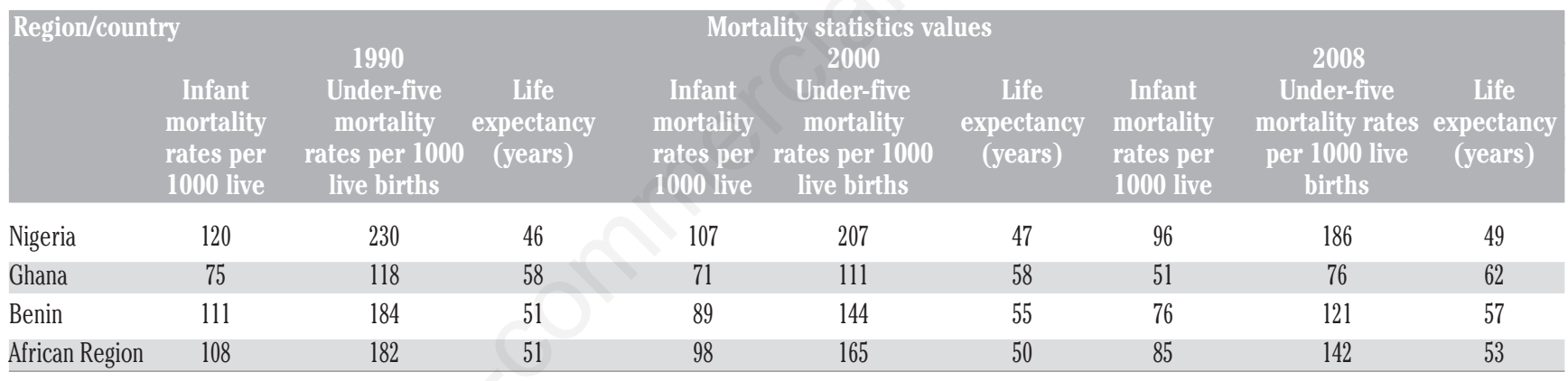

Table 2. A Classification into social classes based on occupation.

$\begin{array}{ccc}\text { Accupation groups } & \text { Social class } \\ \text { A } & \begin{array}{c}\text { Professionals (doctors, lawyers, } \\ \text { engineers, accountants), politicians, } \\ \text { nurses }\end{array} & \text { Upper } \\ \text { B } & \begin{array}{c}\text { Bankers, teachers, journalists, } \\ \text { entrepreneurs }\end{array} & \text { Middle } \\ \text { C } & \text { Lower } \\ & \begin{array}{c}\text { Skilled (technicians, mechanics, } \\ \text { carpenters), semi-skilled and unskilled } \\ \text { workers, petty traders }\end{array} & \\ & \end{array}$

Table 3. A classification into economic classes based on the average monthly earnings.

\begin{tabular}{ccc} 
& $\begin{array}{c}\text { Average monthly } \\
\text { earnings in Naira }\end{array}$ & Income class \\
A & Less than 10,000 & Low income earners \\
B & $10,000-20,000$ & Middle income earners \\
C & $20,000-50,000$ & High income earners \\
\hline D & $50,000-100,000$ & \\
E & 100,000 and above & \\
\hline
\end{tabular}

Table 4. Comparative relationship of the socio-economic status indices of the respondents.

\begin{tabular}{lcccccc} 
& \multicolumn{3}{c}{ Average monthly income } & & \multicolumn{3}{c}{ Level of education } \\
Social class & High No. (\%) & Middle No. (\%) & Low No. (\%) & Secondary No. (\%) & Tertiary No. (\%) & Post-graduateNo. (\%) \\
Upper & $67(65.69)$ & $3(25.00)$ & $1(1.11)$ & $2(2.86)$ & $38(63.33)$ & $31(75.61)$ \\
Middle & $14(13.73)$ & $3(25.00)$ & $6(6.67)$ & $4(5.71)$ & $10(16.67)$ & $9(21.95)$ \\
Lower & $3(2.94)$ & $5(41.67)$ & $67(74.44)$ & $64(91.43)$ & $12(20.00)$ & $1(2.44)$ \\
\hline
\end{tabular}

The omitted difference for each column indicates the proportion of data that is unavailable. 
$12.861 \pm 4.532$ and $10.615 \pm 4.313$ respectively. The scores for the high and low-income earners were $12.535 \pm 4.730$ and $10.895 \pm 3.953$ respectively. Most (81.86\%) of the respondents knew more than 8 of the 16 common health conditions tested.

No statistically significant differences $(\mathrm{P}>0.05)$ were noticed amongst the upper and lower social class groups as well as the high and low income earners as regards their perceived uses of health facilities and the determinants of health facility usage and preference. Concerning the perceived uses of health facilities, the respondents think that it's a place to get treatment (34.84\%), medical enlightenment (25.50\%), medical check-up (23.80\%), a place to find out illnesses affecting someone (15.30\%) and others (0.57\%). The reasons for use of health facility by the respondents include, for treatment of illness (37.98\%), regular check-ups (21.36\%), diagnosis of illness $(16.02 \%)$, to learn of medical issues (13.06\%), if I think I am ill (10.98\%) and others $(0.59 \%)$. Preference for health facility by the respondents had reasons ranging from good treatment outcome (31.88\%), ease of access (21.56\%), nice/kind staff (16.25\%), affordability (15.23\%), proximity (10.94\%) and others (3.75\%).

The preferred health facility for upper and lower social class groups showed no significant difference $(\mathrm{P}>0.05)$, this was not the case for the high and low-income earners who showed differences $(\mathrm{P}<0.05)$. The used health facility showed statistically significant difference $(\mathrm{P}<0.05)$ amongst the compared social class and income earner groups, this is presented in Table 5.

The commonly used health-care giver and that used when last ill by Port Harcourt city residents showed statistically significant $(\mathrm{P}<0.05)$ differences across the social class and income earner groups. The reasons for selection of health-care giver also differed significantly $(\mathrm{P}<0.05)$ between the social class and income earner groups; the values are as presented in Table 6 .

The determinants of the selection of healthcare giver used showed statistically significant $(\mathrm{P}<0.05)$ differences between the social class and income earner groups. The upper socioeconomic class had competence and previous good treatment outcomes as the major determinants for selection of Health care giver; this was not the case for the lower socio-economic class for whom previous good treatment outcome was the most significant factor, this is as shown in Table 7.

Concerning the effect of severity of illness on choice of health-care giver sought; the upper socio-economic class sought after a doctor mostly ( $60.87 \%$ and $58.95 \%$ for upper social class and high income earners respectively) in less serious illnesses and this trend continued even more for more serious illnesses (88.89\% and $93.81 \%$ for upper social class and high income earners respectively); this was not in accord with the findings for the lower socioeconomic class, it is presented in Table 8.

Table 5. The preferred and used health facilities by Port Harcourt city residents.

\begin{tabular}{|c|c|c|c|c|c|c|}
\hline & $\begin{array}{l}\text { Government } \\
\text { hospitals }\end{array}$ & $\begin{array}{l}\text { Health centres } \\
\text { and clinics }\end{array}$ & $\begin{array}{c}\text { Private hospitals } \\
\text { facilities }\end{array}$ & Pharmacies & Un-orthodox health & Others \\
\hline All respondents & $51.28 / 34.08$ & $5.98 / 10.76$ & $30.34 / 33.18$ & $4.70 / 8.07$ & $12.56 / 2.14$ & $5.56 / 1.35$ \\
\hline Upper social class & $55.29 / 41.33$ & $3.53 / 4.00$ & $37.65 / 46.67$ & $0.00 / 1.33$ & $0.00 / 6.67$ & $3.53 / 0.00$ \\
\hline Lower social class & $43.75 / 21.65$ & $7.29 / 19.59$ & $28.13 / 22.68$ & $7.29 / 12.37$ & $3.13 / 21.65$ & $10.42 / 2.06$ \\
\hline High income earners & $58.26 / 42.86$ & $4.35 / 2.86$ & $33.04 / 45.71$ & $1.74 / 3.81$ & $0.00 / 4.76$ & $2.61 / 0.00$ \\
\hline Low income earners & $44.76 / 24.51$ & $8.57 / 20.59$ & $23.81 / 18.63$ & $8.57 / 11.76$ & $4.76 / 21.57$ & $9.52 / 2.94$ \\
\hline
\end{tabular}

Values are presented as follows: preferred health facilities, not in italics; used health facilities, in italics.

Table 6. Distribution of commonly used health-care givers and those used when last ill by Port Harcourt residents.

\begin{tabular}{|c|c|c|c|c|c|c|}
\hline & Herbalist & Spiritualist & Pharmacist & Nurse & Doctor & Others \\
\hline All respondents & $0.95 / 0.90$ & $0.00 / 0.90$ & $22.86 / 19.82$ & $10.48 / 13.06$ & $62.86 / 62.16$ & $2.86 / 3.15$ \\
\hline Upper social class & $0.00 / 0.00$ & $0.00 / 0.00$ & $10.13 / 9.76$ & $8.86 / 12.20$ & $78.48 / 75.61$ & $2.53 / 2.44$ \\
\hline Lower social class & $2.50 / 2.20$ & $0.00 / 2.20$ & $42.50 / 32.97$ & $13.75 / 14.29$ & $38.75 / 46.15$ & $2.50 / 2.20$ \\
\hline High income earners & $0.00 / 0.00$ & $0.00 / 0.00$ & $10.68 / 11.32$ & $6.80 / 9.43$ & $79.61 / 76.42$ & $2.91 / 2.83$ \\
\hline Low income earners & $2.30 / 2.02$ & $0.00 / 2.02$ & $36.78 / 28.28$ & $13.79 / 15.15$ & $43.68 / 48.48$ & $3.45 / 4.04$ \\
\hline
\end{tabular}

Values are presented as follows: commonly used health-care giver, not in italics; used when last ill health-care giver, in italics.

Table 7. Determinants of selection of used health-care giver by Port Harcourt residents.

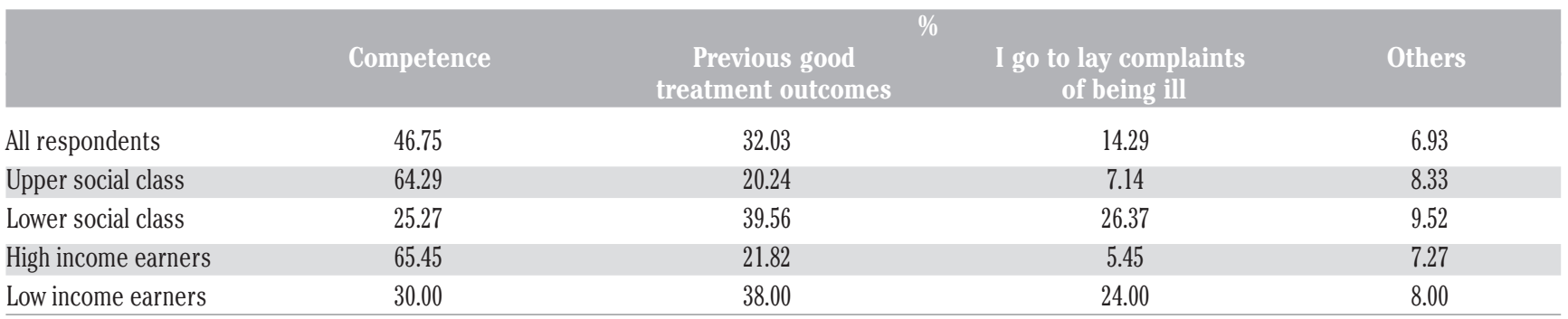




\section{Discussion}

Most Port Harcourt city residents think that all peoples are not equally healthy; they accepted educational level of at least tertiary and high income earnings as determinants of healthiness; this was in keeping with Gupta's ${ }^{13}$ findings (high educational status and high income earnings reduced the probability for falling sick), this finding however showed discord with Malanyaon ${ }^{14}$ who reported that the health conditions of the rich and poor showed no difference. The educated are likely to procure preventive and curative health services more readily as they are able to seek and access health information; in addition, they are in better positions to earn high. Although wealth may not have a direct bearing on the health status in isolation, it may however confer an increased ability to access health care as cost barriers may be lifted for such people. Other determinants of healthiness accepted in order of magnitude of acceptance - include: adequate knowledge on health issues, proper dieting, regular medical check-ups, having resources to take care of self, etc. Having regular medical check-ups, prompt treatment of diseases and updating health knowledge are accepted by Port Harcourt residents as major ways by which a state of wellness can be maintained.

The actions taken by Port Harcourt residents when ill include: seeking for health-help from available sources, resting, resting alongside seeking for health help, seeking for advice from the significant others, etc; this is in keeping with the findings of Peng et al. ${ }^{15}$ who in Beijing showed that when ill, most people would see a doctor or self-medicate. When ill, most persons would generally take actions towards getting relief, the remedial choice would however vary in line with the other determining factors. Most of the residents had an above average knowledge of some common health conditions tested.

The Port Harcourt residents' perception of the uses of health facilities includes: being a place to get treatment, medical enlightenment, medical check-ups, diagnostics etc. These were similar to the actual reasons for their use, which were mainly (in decreasing order of acceptance): for treatment of illness, medical check-up, diagnostics, medical enlightenment etc. These may have accounted for the difference in health facility used by the upper and lower socio-economic classes: the upper used mostly Government and private hospitals and clinics, this is in keeping with Gupta's ${ }^{13}$ finding that the high income earners used Government health facilities more than the low income earners; this also showed congruence with Case et al. ${ }^{16}$ where most of the adults who used a public clinic also saw a private doctor. The Upper classed reside in areas with adequate distribution of health facilities (especially Government and Private Hospitals and clinics), in addition, their high earnings would boost their choosing power for health facilities irrespective of location and cost. The lower class in addition to use of Government and Private Hospitals and Clinics also significantly used health centres and un-orthodox health facilities, being congruent with the report of Borah et al. ${ }^{17}$ that showed the use of public and un-orthodox health facilities by rural community dwellers; the health facility choices here are for reasons ranging from cost and proximity to the local acceptance of the facilities, this is so as within the lower class residential areas, low expenditure setups are rampant to meet with the needs of these persons; the local primary health care facilities would also have some patronage as well.

The reasons for preference of health facility by Port Harcourt residents were similar for the upper and lower socio-economic classes, they include: good treatment outcome, easy access, nice/kind staff, affordability, proximity etc; this was in accord with the report of Nonye et al. ${ }^{18}$ that showed that confidence of cure at place of treatment was the most important determinant of preference for any health facility. Puwar $^{19}$ however reported than the most important factors in the use of public health facilities are free or inexpensive treatment, while private health facility use is mainly determined by its accessibility and good repu- tation. People are generally tilted towards having more benefit for their money and are thus expected to be willing to pay less for services rendered especially in economic poor settings where cost can be a significant factor affecting choice of health facility; however, in the presence of abundant resources, service quality is expected to top the list of the reasons for choosing a facility. Concerning the preferred health facility by Port Harcourt residents, the upper and lower social classes were similar; this was not the case for the high and low income earners who had different preferences; albeit, they prefer the Government and Private Hospitals and Clinics (Government was more preferred than the Private) to other health facilities, just like the upper and lower social classes. This was congruent with Malanyaon's ${ }^{14}$ findings in the Philippines. The choice of Government over Private facilities is especially because of the Government's Health Subsidy packages that tend to even out the social class barrier here.

The medical doctor is the health-care giver of choice for the upper socio-economic classed Port Harcourt residents; the lower socio-economic classed residents would mostly see a doctor but, more significantly see a pharmacist and also a nurse; this finding mirrored those in a report from Ibarapa Local Government area in Nigeria, where the traders studied mostly see a patent drug seller, ${ }^{20}$ it was also in keeping with findings from rural populations in Bangladesh ${ }^{21}$ as well as the findings by Case et $a .^{16}$ in Northern KwaZulu-Natal where almost all the adults would see a western medical provider. The major determinants of selection of health-care giver by the upper socioeconomic class were competence and previous good treatment outcomes; the lower class had good treatment outcomes as their major determinant. The doctor is expected to standout as the most sort after health care provider, however the factors like overall time spent for consultation with a doctor in relation to self-medicating or seeking health-help from various lower cadre health personnel, to proximity and thus cost implications, may deter people from seeing a doctor at all times, especially if they get

Table 8. Distribution of health-care giver used by Port Harcourt residents with varying illness severity.

\begin{tabular}{lcccccc} 
& & & & & \\
& Herbalist & Spiritualist & Pharmacist & Nurse & Doctor & Others \\
All respondents & $4.50 / 0.00$ & $0.50 / 0.00$ & $29.00 / 12.18$ & $17.50 / 2.54$ & $46.50 / 83.76$ & $2.00 / 1.52$ \\
Upper social class & $1.45 / 0.00$ & $0.00 / 0.00$ & $20.29 / 6.94$ & $14.49 / 4.17$ & $60.87 / 88.89$ & $2.90 / 0.00$ \\
Lower social class & $10.00 / 0.00$ & $1.25 / 0.00$ & $33.75 / 24.68$ & $16.25 / 2.60$ & $36.25 / 70.13$ & $2.50 / 2.60$ \\
High income earners & $0.00 / 0.00$ & $0.00 / 0.00$ & $26.32 / 5.15$ & $12.63 / 1.03$ & $58.95 / 93.81$ & $2.11 / 0.00$ \\
Low income earners & $9.20 / 0.00$ & $1.15 / 0.00$ & $34.48 / 23.17$ & $21.84 / 2.44$ & $31.03 / 70.73$ & $2.30 / 3.66$ \\
\hline
\end{tabular}

Values are presented as follows: health-care giver used for less serious illness, not in italics; health-care giver used for more serious illness, in italics. 
relief from the symptoms. Increasing severity of illness altered the choice of healthcare giver seen by the lower socio-economic class (they stepped to health care givers of higher competence with increasing severity of illness), this was not the case for the upper socio-economic class; they mostly remained fixed to their health care giver, likely because most of them saw a medical doctor as their health-care giver; Malanyaon ${ }^{14}$ also reported a similar finding indicating a change in Health-care giver sought based on varying severity of illness. Treatment failure and or persistence of symptoms following remedial actions are expected to drive the health seeker to try to access the most competent health-care giver, under these circumstances, trivialities of proximity, cost, etc, are set aside as the survival of the patient becomes paramount.

\section{Conclusions}

The highly educated and rich are expected to have a better health status than their contemporaries; and the role of having adequate health knowledge, proper dieting, regular medical check-ups, having resources to take care of self and so on in the acquisition of a good health status by an individual cannot be overemphasized. Hence, particular attention should be paid to enlightening the masses on this.

Most people when ill would definitely seek for health-help, as would Port Harcourt residents. Most commonly, they would present to either a Public or Private Hospital or clinic; especially on account of previous good treatment outcome, but also for the accessibility, staff behaviour, affordability and proximity etc. It is thus incumbent on the Health personnel to enhance the quality of health services provided, while the Government (being the health policy makers) should place importance on the quality control and assurance of the health services rendered by the health facilities.

The expected roles of health facilities such as medical enlightenment, diagnostics and therapeutics should be appropriately distributed to all levels of health care, thus making the erstwhile un-orthodox health facilities to be competitively less relevant to the healthcare seeker, especially the lower socio-economic class who may not have all it takes (knowledge and finances) to seek for optimally acceptable health care.

The fact that most people would see a doctor is good to know; the significant percentage that would see a nurse or pharmacist as health-care giver is worrisome, this only buttresses the need for enlightenment of the populace on the roles of the varying cadres of health-care givers. The health-care giver seen is determined largely by competence, previous treatment outcomes and severity of illness.

The upper socio-economic class has better health-seeking behaviours than the lower as evidenced by their use of more competent health caregivers and better choice of health facilities.

\section{References}

1. Sen AK. Health in development. Bull World Health Organ 1999;77:619-23.

2. Lucas A0, Gilles HM. Short textbook of public health medicine for the Tropics. 4 th ed. Malta: Book Power; 2009. p 17.

3. Ward H, Mertens TE, Thomas C. Healthseeking behaviour and the control of sexually transmitted disease. Health Pol Plan 1996;12:19-28.

4. Asakitikpi AE. Born to Die: the Ogbanje phenomenon and its implication on childhood mortality in southern Nigeria. Anthropologist 2008;10:59-63.

5. Ahmed SM. Exploring health-seeking behaviour of disadvantaged populations in rural Bangladesh. Stockholm: Karolinska University Press; 2005. p 44.

6. Vaughan JP, Morrow RH, eds. Manual of epidemiology for district health management. Geneva: World Health Organization; 1989. pp 20, 188.

7. Gupta MC, Mahajan BK. Textbook of preventive and social medicine. 3rd ed. New Delhi: Jaypee Brothers Medical Publishers Ltd; 2005. p 414.

8. Waddell T, ed. World Health Statistics 2010. Geneva: World Health Organization; 2010. Available from: http//www.who.int/gho/publications/world_health_statistics/en/index.html Accessed: November 8, 2010.

9. Katung PY. Socio-economic factors responsible for poor utilization of PHC services in rural community in Nigeria. Niger $\mathrm{J}$ Med 2001;10:28-9.

10. Navaneetham K, Dharmalingam A.
Utilization of maternal health care services in Southern India. Soc Sci Med 2002;55:1849-69.

11. Shaikh BT, Hatcher J. Health seeking behaviour and health service utilisation in Pakistan: challenging the policy makers. J Public Health 2005;27:49-54.

12. Lwanga SK, Tye C, Ayeni 0, eds. Teaching health statistics: lesson and seminar outlines. 2nd ed. Geneva: World Health Organization; 1999. Available from: http://whqlibdoc.who.int/publications/1999/9241545186_eng_parts2-3.pdf Accessed: November 8, 2010.

13. Gupta I, Dasgupta P. Health-seeking behaviour in urban Delhi: an exploratory study. World Health Population 2000;3(2).

14. Malanyaon $\mathrm{OQ}$. Health-seeking behaviour of urban poor communities. Makati: Philippines Institute for Development Studies; 1995. Discussion Paper series No 95-13. Available from: http//issuu.com/ryacat/docs/pidsdps9513

15 Peng Y, Chang W, Zhou H, et al. Factors associated with health-seeking behavior among migrant workers in Beijing, China. BMC Health Serv Res 2010;10:69.

16. Case A, Menendez A, Ardington C. Health seeking behaviour in northern KwaZuluNatal. Africa Centre for Health and Population Studies; 2005. Available from: http:/www.princeton.edu/rpds/papers/pdfs/ case_etal_hsb.pdf Accessed: September 13, 2010.

17. Borah PK, Dutta P, Phukan AC, Mahanta J. Health seeking behaviour among the fever cases during and outbreak of malaria in Assam. J Hum Ecol 2004;15:195-7.

18. Nonye AP, Oseloka EC. Health-seeking behaviour of mentally ill patients in Enugu, Nigeria. South Africa J Pub Health 2009;15:19-22.

19. Puwar T, Kumpavat B, Trivedi K. Pattern of morbidity and health seeking behavior in a slum area of Ahmedabad City in India. Internet J Health 2009;9(2).

20. Ige K, Nwachukwu C. Health care seeking behaviour among market traders In Ibarapa Central Local Government, Nigeria. Internet J Health 2009;9(2).

21. Ahmed SM. Disease patterns, treatment practices and drug requirements in rural Bangladesh: a review of five studies. Dhaka: Centre For Health and Population Research, ICDDR,B. 1999; Working Paper No. 119. 